\title{
Substrate Specificity of Human Cytochrome P450 (CYP) 2C Subfamily and Effect of Azole Antifungal Agents on CYP2C8
}

Toshiro Niwa, Yurie Imagawa

School of Pharmacy, Shujitsu University, 1-6-1 Nishigawara, Naka-ku, Okayama 703-8516, Japan.

Received, August 10, 2016; Revised, October 7, 2010; Accepted, October 27, 2016; Published, October 31, 2016.

\begin{abstract}
PURPOSE: The metabolic activities of aminopyrine $N$-demethylation and tolbutamide methylhydroxylation by the human hepatic cytochrome P450 (P450 or CYP) 2C subfamily were compared and the effects of azole antifungal agent on the drug-metabolizing activity of CYP2C8 were investigated. METHODS: Aminopyrine $N$-demethylation and tolbutamide methylhydroxylation by CYP2C8, CYP2C9, and CYP2C19 were determined by the previous reported methods. The effects of five azole antifungal agents, fluconazole, itraconazole, ketoconazole, miconazole, and voriconazole, on the aminopyrine $N$-demethylation activity by CYP2C8 were investigated. RESULTS: With regard to aminopyrine $N$-demethylation, CYP2C19 had the lowest Michaelis constant $\left(K_{\mathrm{m}}\right)$ and CYP2C8 had the highest maximal velocity $\left(V_{\max }\right)$ among the CYP2C subfamily members. The $V_{\max } / K_{\mathrm{m}}$ values for CYP2C8 were the highest, followed by CYP2C19. For tolbutamide methylhydroxylation, the $K_{\mathrm{m}}$ and $V_{\max }$ for CYP2C19 were three and six times higher than the corresponding values for CYP2C9, and the $V_{\max } / K_{\mathrm{m}}$ value for CYP2C19 was twice that for CYP2C9, whereas hydroxylated tolbutamide formed by CYP2C 8 was not detected. Fluconazole, itraconazole, and voriconazole at a concentration of 2 or $10 \mu \mathrm{M}$ neither inhibited nor stimulated CYP2C8-mediated aminopyrine $N$ demethylation activity at substrate concentrations around the $K_{\mathrm{m}}(5 \mathrm{mM})$. However, ketoconazole and miconazole noncompetitively inhibited CYP2C8-mediated aminopyrine $N$-demethylation with the inhibitory constant values of 1.98 and $0.86 \mu \mathrm{M}$, respectively. CONCLUSION: These results suggest that ketoconazole and miconazole might inhibit CYP2C8 clinically.
\end{abstract}

This article is open to POST-PUBLICATION REVIEW. Registered readers (see "For Readers") may comment by clicking on ABSTRACT on the issue's contents page.

\section{INTRODUCTION}

Cytochrome P450s (P450 or CYP) are a superfamily of enzymes that catalyze the oxidation of a wide variety of endogenous and exogenous compounds, including drugs, carcinogens, and steroids $(1,2)$. The CYP2C subfamily accounts for about $20 \%$ of all $\mathrm{P} 450$ s present in human livers, and is one of the most important $\mathrm{P} 450$ subfamilies because it metabolizes more than $20 \%$ of all therapeutic drugs (3-5). The CYP2C subfamily in human liver comprises three members: CYP2C8, CYP2C9, and CYP2C19. Although the three CYP2C enzymes share more than $82 \%$ amino acid sequence identity, they have rather distinct substrate specificities (6-9).

Multiple drug therapy is a common therapeutic practice, particularly in patients with several diseases or conditions, and many drug-drug interactions involving metabolic inhibition have been reported. Because antibiotics and/or antifungals are co-administered to patients with severe illnesses, there is a possibility of drug-drug interactions (10-12). Macrolide antibacterials, especially troleandomycin and erythromycin, are inhibitors of CYP3A4-mediated metabolism $(1,10)$, and quinolone antibacterial agents, including enoxacin and ciprofloxacin, inhibit the CYP1A2mediated metabolism of drugs $(1,11)$, although, oral cephalosporins such as cefixime and cefdinir neither inhibit nor stimulate the drug-metabolizing activities of P450s (12). Recently, we demonstrated that the penicillin-based antibiotics, amoxicillin and piperacillin, inhibited CYP2C8-mediated aminopyrine $N$-demethylation, although the interactions between these penicillin-based antibiotics and other drugs that are metabolized by P450s would not be clinically significant (13). We also found that CYP2C9 polymorphism affects the ability of azole antifungals to inhibit CYP2C9 (14). However, there have been minimal reports studying the effect of antifungal agents on the drugmetabolizing activity of CYP2C8 (15).

Corresponding Author: Prof. Toshiro Niwa, Ph.D. School of Pharmacy, Shujitsu University; 1-6-1 Nishigawara, Naka-ku, Okayama 703-8516, Japan; E-mail: tniwa@shujitsu.ac.jp 
Thus, in the present study, we compared the metabolic activities mediated by CYP2C8, CYP2C9, and CYP2C19 and investigated the effects of antifungals on CYP2C8-mediated aminopyrine $\mathrm{N}$ demethylation.

\section{METHODS}

\section{Materials}

CYP2C8, CYP2C9, and CYP2C19 expressed in recombinant Escherichia coli (Bactosomes) were obtained from Cypex Ltd (Dundee, UK). Fluconazole, voriconazole, and methylhydroxylated tolbutamide were purchased from Tocris Bioscience (Bristol, UK), and tolbutamide from Sigma-Aldrich (MO, USA). Ketoconazole and miconazole were obtained from LKT Laboratories (St. Paul, MN, USA), and itraconazole from Tokyo Chemical Industry (Tokyo, Japan). All other reagents and organic solvents used were of the highest purity commercially available.

\section{Determination of Human Drug-metabolizing P450 Activities}

Aminopyrine $N$-demethylation and tolbutamide methylhydroxylation were determined in the presence or absence of antifungals, as described previously $(16,17)$. The incubation mixture consisted of human P450, $1 \mathrm{mM}$ of NADPH, $5 \mu 1$ of methanol or $50-1000 \mu \mathrm{M}$ of antifungal agents dissolved in methanol, and $100 \mathrm{mM}$ of potassium phosphate buffer ( $\mathrm{pH}$ 7.4) in a final volume of 0.5 $\mathrm{ml}$. Because itraconazole at a concentration of above $200 \mu \mathrm{M}$ was not dissolved in methanol, the itraconazole concentration in the incubation mixture was $2 \mu \mathrm{M}$. The $\mathrm{P} 450$ concentrations in the mixture were 10 (for aminopyrine $\mathrm{N}$-demethylation) and 40 $\mathrm{pmol} / \mathrm{ml}$ (for tolbutamide methylhydroxylation). Incubation times were 5 (for aminopyrine $\mathrm{N}$ demethylation) or $30 \mathrm{~min}$ (for tolbutamide methylhydroxylation). In the preliminary experiments, the linearity of reaction with P450 concentrations and incubation times was confirmed for each CYP2C subfamily. All data were analyzed using the average of duplicate or triplicate determinations. Michaelis constants $\left(K_{\mathrm{m}}\right)$, maximal velocity $\left(V_{\max }\right)$, and inhibitory constants $\left(K_{\mathrm{i}}\right)$ were determined by performing Michaelis-Menten kinetics using nonlinear least squares regression by means of MULTI (18).

\section{RESULTS}

The kinetics of aminopyrine $\mathrm{N}$-demethylation by CYP2C8, CYP2C9, and CYP2C19 were evaluated by fitting the values into the Michaelis-Menten plots. CYP2C19 had the lowest $K_{\mathrm{m}}$ and CYP2C8 had the highest $V_{\max }$ of the three CYP2C subfamily members. The $V_{\max } / K_{\mathrm{m}}$ values for CYP2C8 were the highest, followed by CYP2C19 (Table 1).

Tolbutamide is a typical substrate of CYP2C9 in vitro and a probe drug used for in vivo drug interaction studies of CYP2C9, as recommended in the guidelines by the European Medicines Agency (EMA) (19) and U.S. Food and Drug Administration (FDA) (20). We recently demonstrated that the $V_{\max }$ and $V_{\max } / K_{\mathrm{m}}$ values of CYP2C9.1 (wild type) and CYP2C9.2 (Arg144Cys) were similar and that CYP2C9.3 (Ile359Leu) had a higher $K_{\mathrm{m}}$ and a lower $V_{\max }$ than CYP2C9.1 and CYP2C9.2 (14). Thus, we compared the tolbutamide methylhydroxylation activities of CYP2C8 and CYP2C19 with that of CYP2C9.1. CYP2C19 had a three-times higher $K_{\mathrm{m}}$ and a six-times higher $V_{\max }$ than CYP2C9, and the $V_{\max } / K_{\mathrm{m}}$ value for CYP2C19 was twice that of CYP2C9 (Table 1). On the other hand, methylhydroxylated tolbutamide catalyzed by CYP2C8 $(40 \mathrm{pmol} / \mathrm{ml})$ at a $100 \mu \mathrm{M}$ substrate concentration was not detected $(<0.1 \mu \mathrm{M})$ after 15 or $30 \mathrm{~min}$ of incubation, suggesting that the $V_{\max } / K_{\mathrm{m}}$ was less than $1 \mu \mathrm{l} / \mathrm{min} / \mathrm{nmol}$.

The inhibitory effects of antifungals on aminopyrine $N$-demethylation mediated by CYP2C 8 were investigated at a $5 \mathrm{mM}$ substrate concentration, which is near the $K_{\mathrm{m}}$ obtained in this study and reported previously (16) (Fig. 1, A). At a $10 \mu \mathrm{M}$ concentration, ketoconazole and miconazole inhibited the reaction by $61.2 \%$ and $76.2 \%$, respectively, whereas fluconazole $\left(\begin{array}{lll}10 & \mu \mathrm{M}\end{array}\right)$, itraconazole $(2 \mu \mathrm{M})$, and voriconazole $(10 \mu \mathrm{M})$ had neither inhibitory nor stimulatory effects against CYP2C8. Ketoconazole and miconazole noncompetitively inhibited CYP2C8 activity and the estimated $\mathrm{K}_{\mathrm{i}}$ values were 1.98 and $0.86 \mu \mathrm{M}$, respectively (Fig. 1, B and C).

\section{DISCUSSION}

Although paclitaxel 6 $\alpha$-hydroxylation and amodiaquine $N$-deethylation are typical metabolic reactions catalyzed by CYP2C $8(1,19,20)$, the metabolites are very expensive and thus rarely purchased. We previously demonstrated that several human hepatic P450s, including CYP2C8, CYP2C9, and CYP2C19, exhibit aminopyrine $N$ demethylation activity (16). Tolbutamide is a typical substrate of CYP2C9 in vitro and a probe drug used for in vivo drug interaction studies as recommended in the guidance by EMA (19) and by FDA (20); however, tolbutamide methylhydroxylation was 
catalyzed by not only CYP2C9 but also CYP2C19 (8). In the present study, CYP2C19 showed a higher $K_{\mathrm{m}}$ and $V_{\max }$ than that shown by CYP2C9 and the $V_{\max } / K_{\mathrm{m}}$ value for CYP2C19 was twice that of CYP2C9, whereas methylhydroxylated tolbutamide catalyzed by CYP2C8 was not detected. For aminopyrine $N$-demethylation, CYP2C19 had the lowest $K_{\mathrm{m}}$ and CYP2C8 and CYP2C19 had the highest $V_{\max }$ of the three CYP2C subfamilies; the $V_{\max } / K_{\mathrm{m}}$ for CYP2C8 was the highest, followed by CYP2C19.
The present results are consistent with those in a previous report that aminopyrine $N$-demethylation activities at a $2 \mathrm{mM}$ substrate concentration, which is near the $K_{\mathrm{m}}$, were highest for CYP2C8 and CYP2C19 (15). These results suggest that aminopyrine $N$-demethylation activity could be used for in vitro drug-drug interaction studies on CYP2C8 (13) at a lower cost, although further comparative studies between aminopyrine $N$-demethylation and the typical metabolic reactions such as paclitaxel $6 \alpha$-hydroxylation and amodiaquine $N$-deethylation might be necessary.

Table 1. Aminopyrine $N$-demethylation and tolbutamide methylhydroxylation activities mediated by CYP2C8, CYP2C9, and CYP2C19.

\begin{tabular}{|c|c|c|c|c|c|c|c|}
\hline \multirow[b]{2}{*}{$\mathrm{P} 450$} & \multirow{2}{*}{$\begin{array}{l}\text { Enzyme } \\
\text { Expression }\end{array}$} & \multicolumn{3}{|c|}{ Aminopyrine $N$-demethylation } & \multicolumn{3}{|c|}{ Tolbutamide methylhydroxylation } \\
\hline & & $\begin{array}{c}K_{\mathrm{m}} \\
(\mathrm{mM})\end{array}$ & $\begin{array}{c}V_{\max } \\
(\mathrm{nmol} / \mathrm{min} / \mathrm{nmol})\end{array}$ & $\begin{array}{c}V_{\max } / K_{\mathrm{m}} \\
(\mu \mathrm{l} / \mathrm{min} / \mathrm{nmol})\end{array}$ & $\begin{array}{c}K_{\mathrm{m}} \\
(\mu \mathrm{M})\end{array}$ & $\begin{array}{c}V_{\max } \\
(\mathrm{nmol} / \mathrm{min} / \mathrm{nmol})\end{array}$ & $\begin{array}{c}V_{\max } / K_{\mathrm{m}} \\
(\mu 1 / \mathrm{min} / \mathrm{nmol})\end{array}$ \\
\hline CYP2C8 & E. coli & $3.0 \pm 0.4$ & $185.6 \pm 8.2$ & 62.8 & - & - & $(<1)$ \\
\hline CYP2C9.1 & E. coli & $10.9 \pm 2.9$ & $75.0 \pm 6.7$ & 6.9 & $98.1 \pm 15.4(14)$ & $2.1 \pm 0.1(14)$ & $21(14)$ \\
\hline CYP2C9.2 & E. coli & - & - & - & $130.4 \pm 48.3(14)$ & $2.3 \pm 0.3(14)$ & $18(14)$ \\
\hline CYP2C9.3 & E. coli & - & - & - & $334.8 \pm 77.2(14)$ & $0.91 \pm 0.09(14)$ & $2.7(14)$ \\
\hline CYP2C19 & E. coli & $1.3 \pm 0.1$ & $32.6 \pm 0.6$ & 26.0 & $346 \pm 23$ & $13.7 \pm 0.4$ & 39 \\
\hline CYP2C8 & Yeast & $5.3(16)$ & $188(16)$ & $36(16)$ & - & - & - \\
\hline CYP2C19 & Yeast & $0.31(16)$ & $105(16)$ & $333(16)$ & - & - & - \\
\hline
\end{tabular}

Values are mean \pm S.D. of the data set using a nonlinear kinetic analysis from mean values obtained in duplicate at each substrate concentration. The 16 in parentheses is the reference for the yeast data. 
(A)

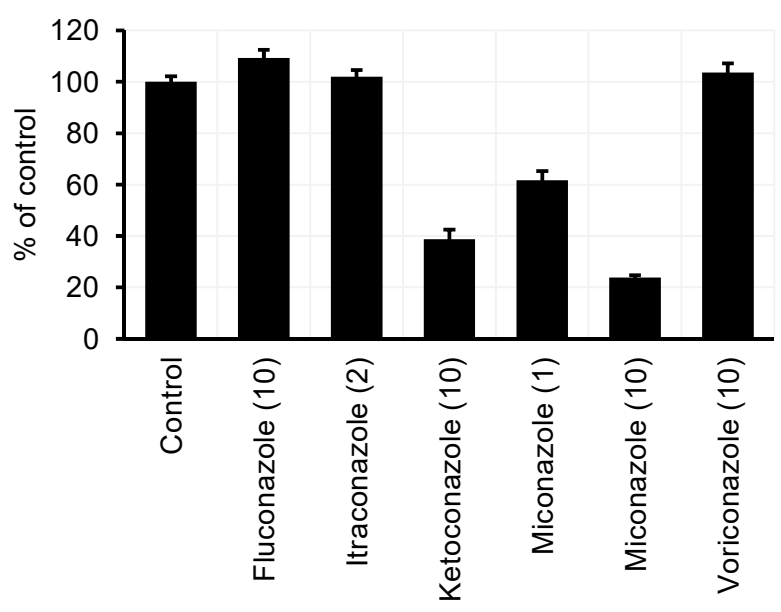

(B)

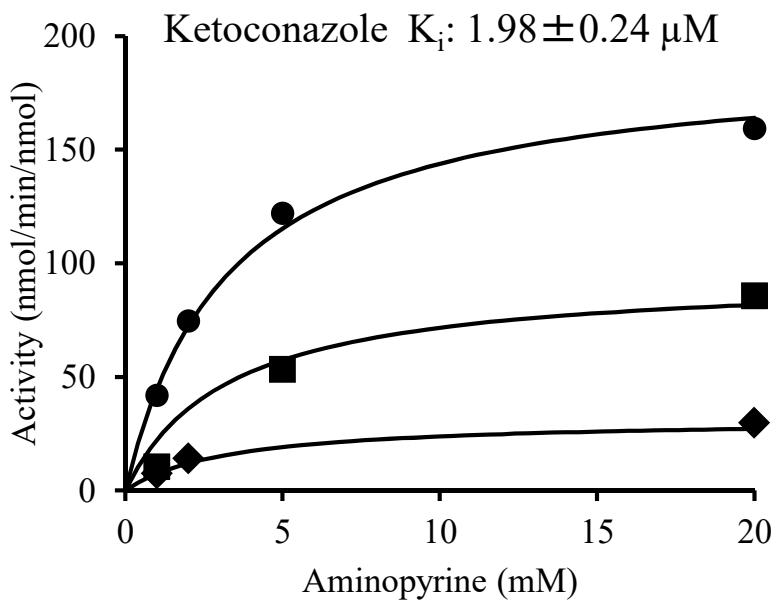

(C)

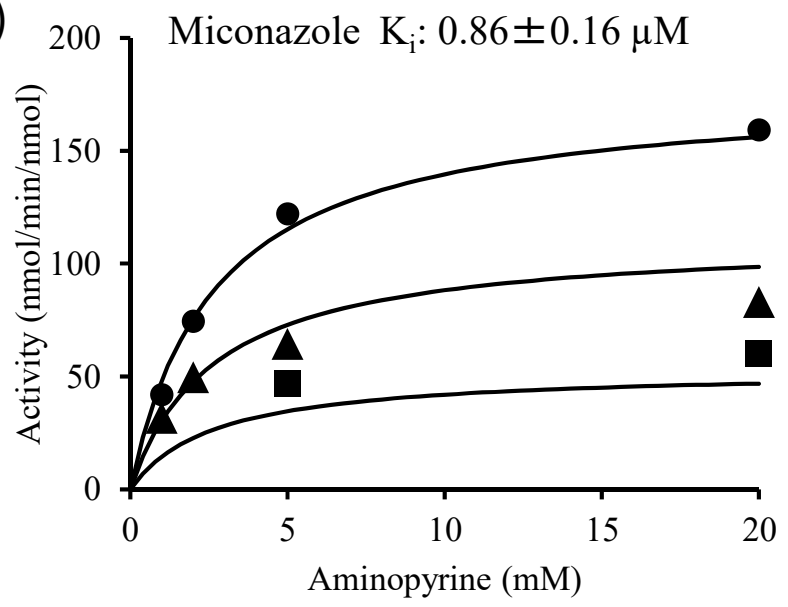

Figure 1. Inhibitory effects of azole antifungals against CYP2C8-mediated aminopyrine $\boldsymbol{N}$-demethylation activity. Inhibitory effects of azole antifungals (A), ketoconazole (B) and miconazole (C). (A) Data are means \pm S.D. ( $\mathrm{n}=3$ ). Values in parentheses are the concentrations of antifungals in the incubation mixture $(\mu \mathrm{M})$. (B), (C): All data were analyzed using the average of duplicate determinations. $\mathrm{K}_{\mathrm{i}}$ values and the standard deviations as indexes of the precision of the calculated parameters were determined by performing Michaelis-Menten kinetics using nonlinear least squares regression by means of MULTI (18). $\bullet: 0 \mu \mathrm{M}, \boldsymbol{\Delta}: 0.5 \mu \mathrm{M}, \bullet: 2 \mu \mathrm{M}, \diamond: 10 \mu \mathrm{M}$. 
In the present study, the relative affinity and/or strength, demonstrated as kinetic parameters such as $K_{\mathrm{m}}, V_{\max }$, and $K_{\mathrm{m}} / V_{\max }$, of aminopyrine $N$ demethylation and tolbutamide methylhydroxylation among CYP2C8, CYP2C9, and CYP2C19 were reaction-dependent. We have previously reviewed the comparison of these kinetic parameters of the CYP2C subfamily members for 74 metabolic reactions of 45 substrates (9). In these reactions, the kinetic behaviors of these CYP2C subfamilies depend on the metabolic reaction, although the ratios of $V_{\max } / K_{\mathrm{m}}$ for CYP2C19/CYP2C9 and CYP2C8/CYP2C19, but not for CYP2C8/CYP2C9, were more closely correlated with $K_{\mathrm{m}}$ values than with $V_{\max }$ values. This suggests that the differences in affinity may be more important than the differences in capacity for the substrate/reaction specificity of CYP2C subfamilies, especially for CYP2C19 (9). Further investigation, for instance, using three-dimensional structural analysis such as molecular docking simulation (21) is required.

Ketoconazole and miconazole noncompetitively inhibited aminopyrine $N$-demethylation catalyzed by CYP2C8, whereas no inhibition was observed for fluconazole, itraconazole, and voriconazole (Fig. 1). Ketoconazole has been recognized as a weak inhibitor of CYP2C8 as listed in US FDA Guidance for Industry - Drug Interaction Studies (2012) (22), however, there were few reports in terms of the inhibition of CYP2C8 by miconazole (15). It has been established that imidazole and triazole compounds, including azole antifungals, reversibly inhibit drug-metabolizing P450s by heme-nitrogen interactions $(23,24)$. Fluconazole can exhibit competitive, noncompetitive, or mixed-type inhibition against CYP3A4 (14,15,25-28). Itraconazole competitively inhibited CYP3A4 $(15,17,27,29)$. On the other hand, it has been reported that fluconazole and voriconazole exhibited mixed-type inhibition and competitive inhibition, respectively, against CYP2C9 $(14,15,24,30)$. We recently reported that voriconazole noncompetitively inhibited tolbutamide hydroxylation catalyzed by CYP2C9.1 (wild type) and CYP2C9.3, whereas fluconazole and voriconazole competitively inhibited the hydroxylation catalyzed by CYP2C9.2 and fluconazole competitively inhibited the reaction catalyzed by CYP2C9.1 (14). Thus, the inhibition type seems to be different among substrates, inhibitors (azole antifungals), P450s, and/or other experimental conditions.

The $K_{\mathrm{i}}$ values of ketoconazole for CYP2C8 obtained in the present study $(1.98 \mu \mathrm{M})$ was lower than the reported $\mathrm{IC}_{50}$ value $(28 \mu \mathrm{M})$, at a substrate concentration of nearly $K_{\mathrm{m}}$ toward CYP2C19mediated $S$-mephenytoin 4 '-hydroxylation activity in human liver microsomes (HLM) (31). For miconazole, the $K_{\mathrm{i}}$ values for CYP2C8 obtained in the present study $(0.86 \mu \mathrm{M})$ was comparable to the reported $\mathrm{IC}_{50}$ value $(0.33 \mu \mathrm{M})$, at a substrate concentration of nearly $K_{\mathrm{m}}$ toward CYP2C19mediated $S$-mephenytoin $4^{\prime}$-hydroxylation activity in HLM (32). When the substrate concentration is lower than the $K_{\mathrm{m}}$ value, the ratio of intrinsic clearance $\left(C L_{\text {int }}\right)$ in the presence and absence of the inhibitor can be expressed by the following equation, independent of the inhibition type, except in the case of uncompetitive inhibition (33-35):

$$
C L_{\text {int }}(+ \text { Inhibitor }) / C L_{\text {int }}(- \text { Inhibitor })=1 /\left(1+\mathrm{I}_{\mathrm{u}} / K_{\mathrm{i}}\right)
$$

where $I_{u}$ is the unbound concentration of the inhibitor. Both ketoconazole and miconazole were reported to increase the plasma concentrations of CYP2C19 substrates such as omeprazole and $S$ mephenytoin, respectively, to more than 1.4 fold $(36,37)$. Thus, these two antifungals might affect drug pharmacokinetics and CYP2C8-mediated drug metabolism. In this regard, however, drugs predominantly metabolized by CYP2C 8 alone are not known. More careful administration of azole antifungals and CYP2C8 substrates is required, although the EMA has already recommended the suspension of marketing authorizations for oral ketoconazole (38), and the FDA limits the usage of Nizoral (ketoconazole) oral tablets due to potentially fatal liver injury, and the risk of drug interactions and adrenal gland problems (39). Topical formulations of ketoconazole (such as creams, ointments, and shampoos) seem to be able to continue to be used because the amount of ketoconazole absorbed through the body is very low in these formulations (38).

In conclusion, the present study suggests that ketoconazole and miconazole but not fluconazole, itraconazole, and voriconazole, might inhibit CYP2C8 clinically, although further clinical drugdrug interaction studies are required.

\section{ACKNOWLEDGEMENT}

This work was supported in part by a grant-in-aid from Ryobi Teien Memory Foundation.

\section{REFERENCES}

1. Rendic S. Summary of information on human CYP enzymes: human P450 metabolism data. Drug Metab. 
Rev, 2002; 34: 83-448. DOI: 10.1081/DMR120001392

2. Niwa, T, Murayama, N, Imagawa, Y, Yamazaki, H. Regioselective hydroxylation of steroid hormones by human cytochromes P450. Drug Metab Rev, 2015; 47: 89-110. DOI: 10.3109/03602532.2015.1011658

3. Shimada $T$, Yamazaki $H$, Mimura $M$, Inui $Y$, Guengerich FP. Interindividual variations in human liver cytochrome P-450 enzymes involved in the oxidation of drugs, carcinogens and toxic chemicals: studies with liver microsomes of 30 Japanese and 30 Caucasians. J. Pharmacol. Exp. Ther, 1994; 270: 414423.

4. Imaoka S, Yamada T, Hiroi T, Hayashi K, Sakaki T, Yabusaki Y, Funae, Y. Multiple forms of human P450 expressed in Saccharomyces cerevisiae. Systematic characterization and comparison with those of the rat. Biochem Pharmacol, 1996; 51: 1041-1050.

5. Williams JA, Hyland R, Jones BC, Smith DA, Hurst S, Goosen TC, Peterkin V, Koup JR, Ball SE. Drugdrug interactions for UDP-glucuronosyltransferase substrates: a pharmacokinetic explanation for typically observed low exposure (AUCi/AUC) ratios. Drug Metab Dispos, 2004; 32: 1201-1208. DOI: 10.1124/dmd.104.000794

6. Ridderström M, Zamora I, Fjellström O, Andersson TB. Analysis of selective regions in the active sites of human cytochromes $\mathrm{P} 450,2 \mathrm{C} 8,2 \mathrm{C} 9,2 \mathrm{C} 18$, and 2C19 homology models using GRID/CPCA. J. Med. Chem, 2001; 44: 4072-4081.

7. Chen Y. Goldstein JA. The transcriptional regulation of the human CYP2C genes. Curr. Drug Metab, 2009, 10: 567-578.

8. Niwa T, Kageyama A, Kishimoto K, Yabusaki Y, Ishibashi F, Katagiri M. Amino acid residues affecting the activities of human cytochrome P450 2C9 and 2C19. Drug Metab Dispos, 2002; 30: 931936.

9. Niwa T, Yamazaki H. Comparison of cytochrome P450 2C subfamily members in terms of drug oxidation rates and substrate inhibition. Curr Drug Metab, 2012; 13: 1145-1159.

10. von Rosensteil NA, Adam D. Macrolide antibacterials. Drug interactions of clinical significance. Drug Saf, 1995; 13: 105-122.

11. Fuhr U, Anders EM, Mahr G, Sörgel F, Staib AH. Inhibitory potency of quinolone antibacterial agents against cytochrome P450IA2 activity in vivo and in vitro. Antimicrob Agents Chemother, 1992; 36: 942948.

12. Niwa T, Shiraga T, Hashimoto T, Kagayama A. Effect of cefixime and cefdinir, oral cephalosporins, on cytochrome $\mathrm{P} 450$ activities in human hepatic microsomes. Biol Pharm Bull, 2004; 27: 97-99.

13. Niwa T, Morimoto M, Hirai T, Hata T, Hayashi M, Imagawa Y. Effect of penicillin-based antibiotics, amoxicillin, ampicillin, and piperacillin, on drugmetabolizing activities of human hepatic cytochromes P450. J Toxicol Sci, 2016; 41: 143-146.
DOI: $10.2131 /$ jts. 41.143

14. Niwa T, Hata T. The effect of genetic polymorphism on the inhibition of azole antifungal agents against CYP2C9-mediated metabolism. J Pharm Sci, 2016; 105: 1345-1348. DOI: 10.1016/j.xphs.2016.01.007

15. Niwa T, Imagawa Y, Yamazaki H. Drug interactions between nine antifungal agents and drugs metabolized by human cytochromes P450. Curr Drug Metab, 2014; 15:651-679.

16. Niwa T, Sato R, Yabusaki Y, Ishibashi F. Katagiri M. Contribution of human hepatic cytochrome P450s and steroidogenic CYP17 to the $N$-demethylation of aminopyrine. Xenobiotica, 1999; 29: 187-193. DOI: 10.1080/004982599238731

17. Niwa $T$, Inoue S, Shiraga T, Takagi A. No inhibition of cytochrome $\mathrm{P} 450$ activities in human liver microsomes by sulpiride, an antipsychotic drug. Biol. Pharm. Bull, 2005; 28: 188-191.

18. Yamaoka K, Tanigawara Y, Nakagawa T, Uno T. A pharmacokinetic analysis program (MULTI) for microcomputer. J Pharmacobiodyn, 1981; 4:879-885.

19. European Medicines Agency. Guideline on the investigation of drug interactions. 6/21/2012. CPMP/EWP/560/95/Rev. 1 Corr. 2** http://www.ema.europa.eu/docs/en GB/document li brary/Scientific guideline/2012/07/WC500129606.p df\#search='European+Medicines + Agency $\% 2 \mathrm{C}+$ dru g+interaction' (21 June 2012)

20. U.S. Food and Drug Administration. Drug Development and Drug Interactions: Table of Substrates, Inhibitors and Inducers. http://www.fda.gov/Drugs/DevelopmentApprovalPr ocess/DevelopmentResources/DrugInteractionsLabe ling/ucm093664.htm\#4 (27 October 2014)

21. Niwa T, Yasumura M, Murayama N, Yamazaki H. Comparison of catalytic properties of cytochromes P450 3A4 and 3A5 by molecular docking simulation. Drug Metab Lett, 2014;8(1):43-50.

22. U.S. Food and Drug Administration. Guidance for Industry - Drug Interaction Studies - Study design, data analysis, implications for dosing, and labeling recommendations. February 2012.

23. Locuson CW, Hutzler JM, Tracy TS. 2007. Visible spectra of type II cytochrome P450-drug complexes: evidence that "incomplete" heme coordination is common. Drug Metab Dispos, 2014; 35:614-622. DOI: $10.1124 / \mathrm{dmd}$.106.012609

24. Conner KP, Vennam P, Woods CM, Krzyaniak MD, Bowman MK, Atkins WM. 1,2,3-Triazole-heme interactions in cytochrome P450: functionally competent triazole-water-heme complexes. Biochemistry, 2012; 51: 6441-6457. DOI: $10.1021 / \mathrm{bi} 300744 \mathrm{z}$

25. Kunze KL, Wienkers LC, Thummel KE, Trager WF. Warfarin-fluconazole. I. Inhibition of the human cytochrome P450-dependent metabolism of warfarin by fluconazole: in vitro studies. Drug Metab Dispos, 1996; 24:414-421.

26. von Moltke LL, Greenblatt DJ, Schmider J, Duan SX, 
Wright CE, Harmatz JS, Shader RI. Midazolam hydroxylation by human liver microsomes in vitro: inhibition by fluoxetine, norfluoxetine, and by azole antifungal agents. J Clin Pharmacol, 1996; 36:783791.

27. Isoherranen $\mathrm{N}$, Ludington SR, Givens RC, Lamba JK, Pusek SN, Dees EC, Blough DK, Iwanaga K, Hawke RL, Schuetz EG, Watkins PB, Thummel KE, Paine MF. The influence of CYP3A5 expression on the extent of hepatic CYP3A inhibition is substratedependent: an in vitro-in vivo evaluation. Drug Metab Dispos, 2008; 36:146-154. DOI: 10.1124/dmd.107.018382

28. Yamazaki H, Nakamoto M, Shimizu M, Murayama N, Niwa T. Potential impact of cytochrome P450 3A5 in human liver on drug interactions with triazoles. $\mathrm{Br}$ J Clin Pharmacol, 2010; 69:593-597. DOI: 10.1111/j.1365-2125.2010.03656.x

29. Akiyoshi T, Saito T, Murase S, Miyazaki M, Murayama N, Yamazaki H, Guengerich FP, Nakamura K, Yamamoto K, Ohtani H. Comparison of the inhibitory profiles of itraconazole and cimetidine in cytochrome P450 3A4 genetic variants. Drug Metab Dispos, 2011; 39:724-728. DOI: 10.1124/dmd.110.036780

30. Jeong S, Nguyen PD, Desta Z. Comprehensive in vitro analysis of voriconazole inhibition of eight cytochrome P450 (CYP) enzymes: major effect on CYPs 2B6, 2C9, 2C19, and 3A. Antimicrob Agents Chemother, 2009; 53:541-551. DOI: 10.1128/AAC.01123-08

31. Baldwin SJ, Bloomer JC, Smith GJ, Ayrton AD, Clarke SE, Chenery RJ. Ketoconazole and sulphaphenazole as the respective selective inhibitors of P4503A and 2C9. Xenobiotica, 1995; 25: 261-270. DOI: $10.3109 / 00498259509061850$

32. Niwa T, Shiraga T, Takagi A. Effect of antifungal drugs on cytochrome P450 (CYP) 2C9, CYP2C19, and CYP3A4 activities in human liver microsomes. Biol Pharm Bull, 2005; 28: 1805-1808.
33. Ito $\mathrm{K}$, Iwatsubo $\mathrm{T}$, Kanamitsu $\mathrm{S}$, Nakajima $\mathrm{Y}$, Sugiyama Y. Quantitative prediction of in vivo drug clearance and drug interactions from in vitro data on metabolism, together with binding and transport. Annu Rev Pharmacol Toxicol, 1998; 38: 461-499. DOI: 10.1146/annurev.pharmtox.38.1.461

34. Ito K, Iwatsubo T, Kanamitsu S, Ueda K, Suzuki H, Sugiyama Y. Prediction of pharmacokinetic alterations caused by drug-drug interactions: metabolic interaction in the liver. Pharmacol Rev, 1998; 50: 387-412.

35. Pharmaceuticals and Medical Devices Agency. Methods of drug interaction studies (PMSB/ELD Notification No. 813; June 4, 2001). http://www.nihs.go.jp/phar/pdf/DiGlEngFinal01120 9.pdf. (4 June 2001)

36. O'Reilly RA, Goulart DA, Kunze KL, Neal J, Gibaldi M, Eddy AC, Trager WF. Mechanisms of the stereoselective interaction between miconazole and racemic warfarin in human subjects. Clin Pharmacol Ther, 1992; 51; 656-667.

37. Böttiger Y, Tybring G, Götharson E, Bertilsson L. Inhibition of the sulfoxidation of omeprazole by ketoconazole in poor and extensive metabolizers of $S$-mephenytoin. Clin Pharmacol Ther, 1997; 62: 384391. DOI: 10.1016/S0009-9236(97)90116-8

38. European Medicines Agency recommends suspension of marketing authorisations for oral ketoconazole.

http://www.ema.europa.eu/ema/index.jsp?curl=page s/news and events/news/2013/07/news detail 001 855.jsp\&mid=WC0b01ac058004d5c1 (26 July 2013).

39. FDA Drug Safety Communication: FDA limits usage of Nizoral (ketoconazole) oral tablets due to potentially fatal liver injury and risk of drug interactions and adrenal gland problems. 26/07/2013. http://www.fda.gov/Drugs/DrugSafety/ucm362415.h tm (26 July 2013). 